\title{
Failure Analysis of Cathode Materials for Energy Storage Batteries in Overcharge Test
}

\author{
Hongwei Wang ${ }^{1, *}$, Ziqiang $\mathrm{Tao}^{1}$, Nianpeng $\mathrm{Si}^{2}$, Yanling $\mathrm{Fu}^{1}$, Tao $\mathrm{Li}^{1}$ and Haiqing Xiao ${ }^{1}$ \\ ${ }^{1}$ Institute of Industrial and Consumer Product Safety, Chinese Academy of Inspection and \\ Quarantine, Beijing Petrochemical Engineering Co., Ltd., Beijing, China \\ ${ }^{2}$ Inspection \& Quarantine Technology Center of Guangdong Entry-Exit Inspection \& Quarantine \\ Bureau of P. R. China, Room 812, Tower B, No.66 Huacheng Avenue, Guangzhou, Guangdong \\ Province, China
}

\begin{abstract}
The micro-analysis of energy storage batteries in overcharge test at $20^{\circ} \mathrm{C}$ temperature was investigated. The results showed as follows: (1) Compared with the normal battery charge at room temperature scanning microscope maps of battery overcharge, the crystal was fractured of the positive surface when the battery was overcharging, and with the increase of experimental time, the crystal fracture is more serious, this is to say that the battery electrolyte decomposition or battery material structure could change by overcharge test. (2) Based on the XRD maps, the characteristic peak position of overcharge test of cathode materials were changed, this showed that the content of cathode material elemental has been destroyed and changed in overcharge test.
\end{abstract}

\section{Introduction}

It is considered that Lithium-ion battery is electric vehicle power supply important development direction the next few years, because the features of Lithium-ion battery is excellent, such as high working voltage, light weight, high Lithium-ion battery specific energy, long cycle life, fast charging, and so on[1-3]. Lithium-ion battery has been more and more widely used in mobile electronic equipment, electric vehicles, as well as national defense and other high-tech industry. Retired lithium-ion battery is often used in the field of energy storage[4-5].

Lithium-ion batteries are usually used constant current constant voltage charging mode. Charging begins to constant current stage, the battery voltage is low, and the charging current is stable in the charge process. As the charge continues, the battery voltage gradually increased to $4.2 \mathrm{~V}$, and the charger should be immediately transferred to the constant voltage charging, charging voltage fluctuations should be controlled within $1 \%$, the charging current gradually reduced. When the current drops to a certain range, into the trickle charge stage, and finally make the battery in a sufficient state. The battery overcharge is continued to charge after a certain charging process. The damage of the lithium battery overcharge is great, and it may be fire or explosion.

\footnotetext{
*Corresponding author: author@email.org
} 
Therefore, the microcosmic change of the positive electrode after the overcharge of the lithium energy storage battery is analyzed, and the change rules of the positive electrode is studied, which provides some basic research data for the improvement of the performance of the energy storage battery.

\section{The overcharge tests}

\subsection{Test sample}

The parameters of sample battery in this paper as follows: 1) The model: domestic battery, rated voltage $3.7 \mathrm{~V}$, rated capacity $10 \mathrm{Ah}$, internal resistance $<6 \mathrm{~m} \Omega$, weight $<320 \mathrm{~g}$; 2) The composing of the battery: the cathode material is $\mathrm{LiMn}_{2} \mathrm{O}_{4}$, the anode material is graphite, the electrolyte is $\mathrm{LiPF}_{6}, \mathrm{EC}$ and $\mathrm{DMC}$, and battery separator is celgard $2325 ; 3$ ) Dimensions: $133 \mathrm{~mm} \times 66 \mathrm{~mm} \times 18 \mathrm{~mm}$.

\subsection{Test instrument}

Maccor battery performance test systems (model M4200), CSZ Thermostat box (model ZPS-16SPHH-101), Bruker D8 focus X instrument and Hitachi S-4800 instrument. The test is shown in Fig. 1.
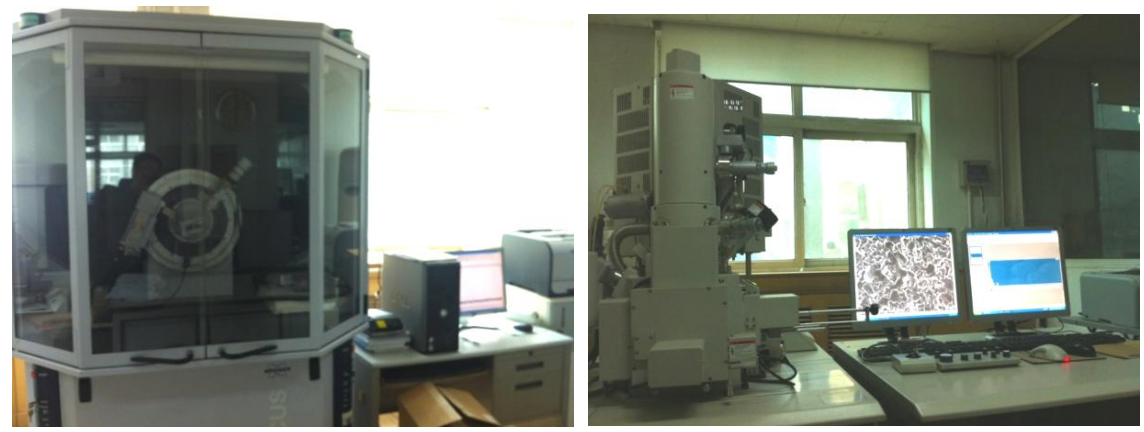

Fig. 1. The overcharge tests.

\subsection{Test method}

1) Each test battery was discharged at a constant current of $2.2 \mathrm{~A}$, to a final discharge voltage $2.7 \mathrm{~V}$, was charged at constant current of $2.2 \mathrm{~A}$ to the $4.2 \mathrm{~V}$, and was charged at constant voltage to $0.2 \mathrm{~A}$. the break of battery charge and discharge is 1 hour. The 10 cycle tests were carried out.

2) The test was carried out in an ambient temperature of $20{ }^{\circ} \mathrm{C} \pm 5{ }^{\circ} \mathrm{C}$. Each test battery was discharged at a constant current of $2.2 \mathrm{~A}$, to a final discharge voltage $2.7 \mathrm{~V}$ that was specified by the manufacturer. Then, Sample batteries was be charged at a constant current of 2.2 A to $5 \mathrm{~V}$.

\section{Results and discussion}

The batteries of rated voltage $3.7 \mathrm{~V}$ were used in this paper, charge terminal voltage is $4.2 \mathrm{~V}$, and the allowable voltage error range is $0.042 \mathrm{~V}$. Figure 2 is the positive of the overcharge battery in accordance with the above method. 


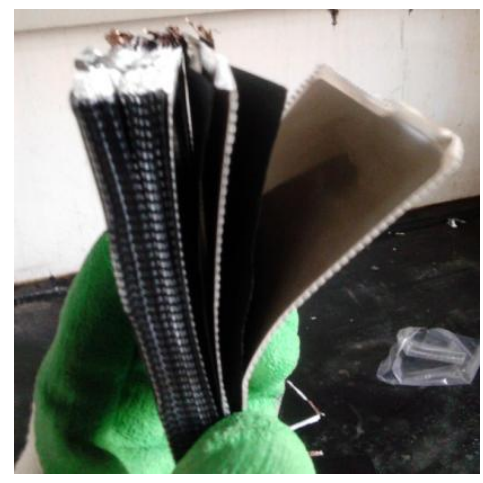

Fig. 2. The positive of the overcharge battery.

SEM morphology of positive electrode of battery in charge and overcharge test is shown in Fig.3 and Fig.4 (magnification of 9000). Energy spectrum element content table of positive after overcharge test is shown in Table1.

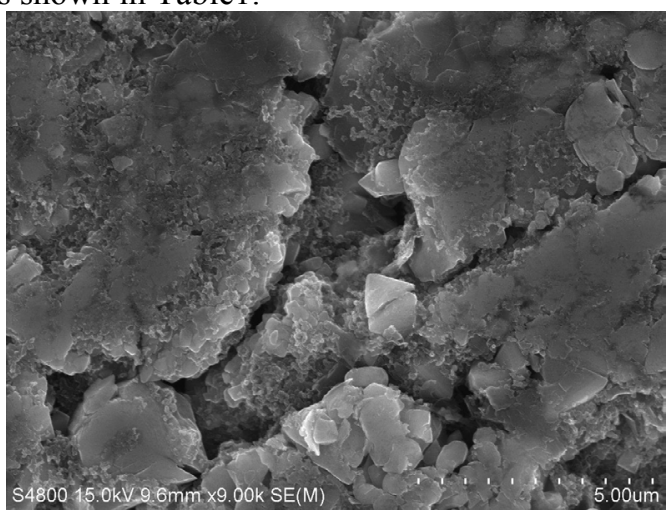

Fig. 3. SEM morphology of positive electrode of battery in charge test.

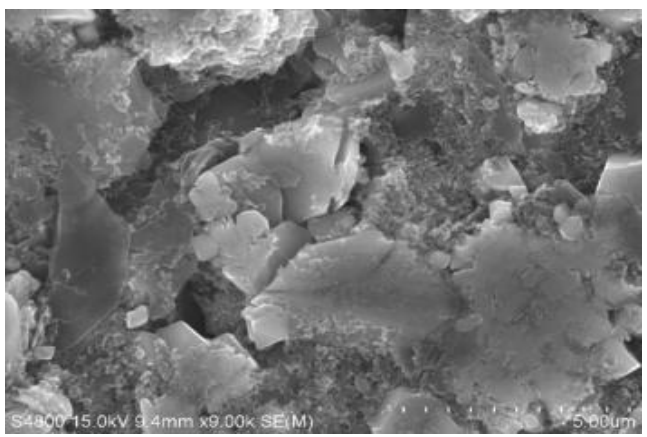

Fig. 4. SEM morphology of positive electrode of battery in overcharge test.

Table 1. Energy spectrum element content table of positive.

\begin{tabular}{|c|c|c|c|}
\hline & Element & Weight percentage /\% & Atomic percentage /\% \\
\hline \multirow{3}{*}{ Overcharge } & $\mathrm{C}$ & 364.67 & 20.80 \\
\cline { 2 - 4 } & $\mathrm{O}$ & 424.78 & 18.19 \\
\cline { 2 - 4 } & $\mathrm{F}$ & 1448.01 & 52.22 \\
\cline { 2 - 4 } & $\mathrm{P}$ & 107.85 & 2.39 \\
\hline \multirow{3}{*}{ Charge } & $\mathrm{C}$ & 832.44 & 69.63 \\
\cline { 2 - 4 } & $\mathrm{O}$ & 250.55 & 15.73 \\
\cline { 2 - 4 } & $\mathrm{F}$ & 239.61 & 12.67 \\
\cline { 2 - 4 } & $\mathrm{P}$ & 34.49 & 1.12 \\
\hline
\end{tabular}


According to Fig.3, Fig.4 and Table 1, the positive structure of battery has been crystallized in overcharge test, and different degrees fracture has been occurred. Compared with SEM morphology of the normal charge and overcharge battery at room temperature, the crystal was fractured of the positive surface when the battery was overcharging, and with the increase of experimental time, the crystal fracture is more serious, this is to say that the battery electrolyte decomposition or battery material structure could change by overcharge test.

Fig. 5 shows the X-ray diffraction image of the positive electrode of the battery after normal charge and overcharge test.

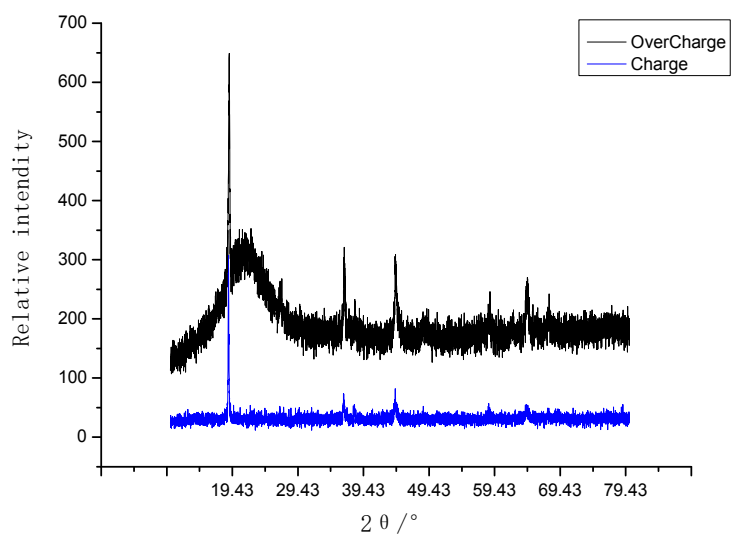

Fig. 5. XRD pattern of positive electrode of battery in charge and overcharge test.

It can be seen from Fig. 5, compared to the normal state of the charge battery, the content and type of positive elements of battery are higher than in overcharge test, overcharge lead to the element content of the battery positive material has been destroyed and changed.

Therefore, the negative capacity than the positive capacity is higher according to the battery design, the gas generated from positive go through the diaphragm complex with cadmium that from negative, and the battery pressure will not be significantly increased under normal circumstances, but if the charging current is too large, or charging time is too long, the oxygen is too late to be consumed, it may cause internal pressure, battery deformation, and other undesirable phenomena. At the same time, its electrical performance will be significantly reduced.

\section{Conclusions}

On the basis of the foregoing test results, analysis and discussions, the conclusion can be obtained as follows:

(1) Compared with the normal battery charge at room temperature scanning microscope maps of battery overcharge, the crystal was fractured of the positive surface when the battery was overcharging, and with the increase of experimental time, the crystal fracture is more serious, this is to say that the battery electrolyte decomposition or battery material structure could change by overcharge test. 
(2) Based on the XRD maps, the characteristic peak position of overcharge test of cathode materials were changed, this showed that the content of cathode material elemental has been destroyed and changed in overcharge test.

The authors would like to acknowledge the financial support provided for this research work by Fund: Fundamental scientific research projects of Chinese Academy of Inspection and Quarantine (2017JK024).

\section{References}

1. H. YU,H. WANG,Y. WANG. et al. PTCA(PART A: PHYS.TEST.) 49: 535-539(2013)

2. H. YU,H. WANG,Y. Fu. et al. 2014 International Conference on Mechanics and Materials Engineering. 673-679(2014)

3. H. Wang, W. Wu, W. Li. et al. Chinese Journal of Power Sources. 38(8): 14301432(2014)

4. L.Liu, S. Tian, Y. Zhu, W. Tang, L.L. Li, Y.P. Wu, J. Chin. Chem. Soc., 59, 12161219 (2012).

5. W. Tang, L. Liu,S. Tian. et al. Electrochemistry Communications 13, 1159-1162(2011) 